\title{
Increasing Extender Viscosity Improves the Quality of Cooled Boar Semen
}

\author{
Maria Cruz Gil Anaya ${ }^{1}$, Francisco Javier Barón ${ }^{2}$, Jesús Manuel Guerrero ${ }^{1}$, Luis Jesús García-Marín ${ }^{1} \&$ Javier Gil $^{3}$ \\ ${ }^{1}$ Research Team of Intracellular Signaling and Technology of Reproduction (SINTREP), Veterinary School, \\ University of Extremadura, Cáceres, Spain \\ ${ }^{2}$ Department of Preventive Medicine and Public Health, Medicine School, Málaga University, Spain \\ ${ }^{3}$ JGPAsesor, Segovia, Spain
}

Correspondence: Maria Cruz Gil Anaya, Research Team of Intracellular Signalling and Technology of Reproduction (SINTREP), Veterinary School, University of Extremadura, Caceres 10003, Spain. Tel: 34-927-257-100 ext. 1303. E-mail: crgil@unex.es

\author{
Received: November 11, 2013 Accepted: December 5, 2013 Online Published: February 15, 2014 \\ doi:10.5539/jas.v6n3p12 URL: http://dx.doi.org/10.5539/jas.v6n3p12
}

\begin{abstract}
The use of several types of gelling extenders for the storage of semen from several domestic species in the solid state has been shown to have beneficial effects on some semen quality parameters. The objective of this study was to evaluate the effect of a new high-viscosity semen extender, Zoosperm ND-5 3D ${ }^{\circledR}$ (Import-Vet, Centelles, Spain), on the the quality of boar spermatozoa at preserved at $17^{\circ} \mathrm{C}$ for 7 days. Sodium alginate was used for the first time to increase the viscosity of the extender for the liquid storage of boar semen. The same extender, but without increased viscosity, was used as a control extender (Zoosperm ND-5 ${ }^{\circledR}$, Import-Vet, Centelles, Spain). Sixteen ejaculates from four Pietrain boars were evaluated for motility (by the CASA system), and for viability, acrosome status, plasma membrane fluidity, externalization of phosphatidylserine at the plasma membrane of the spermatozoa and mitochondrial membrane potential (by flow cytometry). In samples diluted with the Zoosperm ND-5 3D ${ }^{\circledR}$ viscous extender, the STR (straightness) parameter and the number of progressively motile spermatozoa were higher compared to those of the non-viscous extender $(p<0.05)$. In addition, the number of spermatozoa with damaged acrosomes, an unstable sperm plasma membrane and externalization of phosphatidylserine at the plasma membrane was lower in samples treated with the viscous extender $(p<0.05)$. In conclusion, an increase in extender viscosity improves quality of boar spermatozoa following long-term storage.
\end{abstract}

Keywords: Zoosperm ND-5 3D ${ }^{\circledR}$, boar, extender, storage, viscosity

\section{Introduction}

The role that artificial insemination (IA) based on cooled semen technology has played in global boar production is widely acknowledged. Among other advantages, this technology allows for maximizing the genetic potential of high-quality breeding stock. Among the facts that have contributed to the advances in this technology are better knowledge of sow management and physiology, improvements in semen processing and design of better extenders.

Because seminal plasma alone does not allow for long-lasting semen preservation, the addition of an extender permits an increase in the ejaculate volume, extends the average life span of spermatozoa and maintains an adequate fertility level in the sow herd (Gadea, 2003). Because boar spermatozoa are highly susceptible to cold shock, they need to be stored at temperatures of $15-20^{\circ} \mathrm{C}$, which limits storage period.

During the storage of extended boar semen, a further decrease in the fertility potential as a result of the natural ageing process of spermatozoa cannot be prevented. In several studies, functional and structural changes of spermatozoa during storage have been measured. The data include changes in motility, viability, pH, DNA integrity, acrosome intactness, mitochondrial activity, bacterial contamination, tyrosine phosphorylation and more recently, screening for the sperm proteome, cytome and lipidome (De Ambrogi et al., 2006; Dubé, Beaulieu, Reyes-Moreno, Guillemette, \& Bailey, 2004; Huo, Ma, \& Yang, 2002; Martín-Hidalgo et al., 2013; Waberski, Henning, \& Petrunkina, 2011). 
Extenders are a factor influencing the cold shock tolerance of spermatozoa. Over the last 10 years, new extenders for boar semen, both for short-term (1-3 days) and long-term preservation (more than 4 days), have been designed (Riesenbeck, 2011). The use of long-term extenders is suitable in situations where work overload is expected at the AI center, when large sow herds are involved or when seminal doses are prepared from low demand or rarely used boars. They also allow for long-distance transportation of the semen. Artificial insemination with cooled semen is likely to remain the most widely used sperm preservation technology in swine rearing programs, given the excellent fertility results achieved until now (Roca et al., 2006).

An increase in extender viscosity has been shown to improve the quality of stored semen. However, research in boars about this subject is scarce. Corcini et al. (2011) observed that adding gelatin to the short-term Beltsville Thawing Solution (BTS) extender for boar semen produced a less marked fall in the percentage of motile and morphologically normal spermatozoa during the preservation period compared to the samples to which no gelatin was added, although no significant differences between extenders were observed in either parameter (Corcini et al., 2011). Coy, Gadea, Rath and Hunter (2009) showed that the re-suspension of boar spermatozoa in a viscous medium increased the stability of the sperm membrane, decreased reactive oxygen species production and increased the capacity of spermatozoa to penetrate oocytes in vitro. The use of gelling extenders, mostly by the use of gelatin, has proven to be effective in prolonging the preservation of rabbit (López-Gatius et al., 2005; Nagy, Sinkovics, \& Kovacs, 2002; Rosato \& Iaffaldano, 2011), ovine (Yániz et al., 2005) and caprine (Salvador, Yániz, Viudes-de-Castro, Gómez, \& Silvestre, 2006) sperm in a solid state. However, it remains to be seen whether the reported benefits are also applicable to semen stored in a liquid form. Those benefits were attributed to possible effects on sperm sedimentation and the reduction of metabolic activity due to the reduced sperm motility. Alginate or alginic acid is an anionic polysaccharide distributed widely in the cell walls of brown algae. It has a large gelling capacity and is widely used for the microencapsulation of spermatozoa before storing. Microencapsulation in barium alginate membranes has been found to protect sperm cells during storage, preserving morpho-functional characteristics (Spinaci et al., 2013; Torre et al., 2000; Vigo et al., 2002). We could find no reference in the literature to the use of alginate in long-term viscous extenders for the long-term preservation of boar semen in liquid form. For this reason, Import-Vet, S. A. (Centelles, Spain) has designed Zoosperm ND-5 3D ${ }^{\circledR}$ (hereafter 3D), a viscous extender for long-term preservation. This study evaluates for the first time the effectiveness of this new viscous extender in terms of its capacity to preserve the sperm quality of boar semen aliquots after 7 days at $17^{\circ} \mathrm{C}$. In addition, the same extender but without increased viscosity was used as a control extender (Zoosperm ND- ${ }^{\circledR}$, Import-Vet, S. A., hereafter ND-5). On the basis of previous studies of viscous extenders for semen storage in the solid state, our hypothesis is that $3 \mathrm{D}$ will improve the sperm quality of the liquid stored semen.

\section{Materials and Methods}

\subsection{Chemicals and Sources}

ND-5 ${ }^{\circledR}$ and ND-5 3D ${ }^{\circledR}$ were provided by Import-Vet, S. A. (Centelles, Spain). Live/dead spermatozoa viability kits including propidium iodine (PI) and SYBR-14, M540 and YoPro-1 probes were purchased from Molecular Probes (Leiden, The Netherlands). Annexin-V-FITC was obtained from Immnostep (Salamanca, Spain). FITC-PNA was purchased from Sigma-Aldrich ${ }^{\circledR}$ (St. Louis, MO, USA). The coulter isoton II diluent was obtained from Beckman Coulter Inc. (Brea, CA, USA) and the JC-1 (5,5',6,6'-tetrachloro-1,1',3,3' tetraethylbenzymidazolyl carbocyanine iodine) probe was purchased from Life Technologies Ltd. (Grand Island, NY, USA).

\subsection{Sample Preparation and Assessment of Sperm Quality Parameters}

\subsubsection{Sample Preparation}

Sixteen ejaculates from four healthy, sexually mature (2-3 years old) and fertile Pietrain boars were analyzed. The animals belonged to an AI center in Segovia (Spain). The boars were subjected to regular semen collection three times every two weeks for commercial use. All the males were kept in individual pens in a controlled environment $\left(15-20^{\circ} \mathrm{C}\right)$ and all were fed the same diet. The ejaculate was collected using the "gloved hand" technique and was then gently homogenized and divided in two equal parts. After an initial assessment of motility (assessed subjectively by light microscopy at 10X), morpho-anomalies and concentration (both by light microscopy in a Bürker chamber after dilution in $10 \%$ formaldehyde-saline solution at $40 \mathrm{X}$ ), one of the fractions was diluted to a $33 \times 10^{6}$ cells $/ \mathrm{mL}$ final concentration with ND-5 extender and the other fraction, at the same concentration level, was diluted with 3D viscous extender. The composition of the extenders differed only in the hydrocolloid compound (sodium alginate) added to the 3D extender in order to increase viscosity to a 13 centipoises value at $17^{\circ} \mathrm{C}$. Viscosity measurement was performed by a specialized laboratory (Brookfield viscometer, CETAEX, Badajoz, Spain). The quantitative composition is unknown because of commercial interests, so only qualitative composition is done (glucose, sodium citrate, EDTA, sodium bicarbonate, potassium chloride, acetylcysteine, 
MOPS and antibiotics). Both extenders were prepared following the manufacturer's instructions. Dilutions of both ejaculate fractions were carried out within $15 \mathrm{~min}$ after they were obtained. Only those ejaculates containing at least $70 \%$ of motile spermatozoa and less than $20 \%$ of morphologically abnormal spermatozoa were selected for the trial. The diluted semen was then bottled in $90 \mathrm{ml}$ plastic bottles with clip-tops (Import-Vet, S. A., Centelles, Spain).After lowering the temperature of the semen doses to $20-22^{\circ} \mathrm{C}$ over approximately $2 \mathrm{~h}$ at room temperature, 3 bottles of each ejaculate diluted in ND-5 or $3 \mathrm{D}$ were stored at $16-17^{\circ} \mathrm{C}$ until their transport to the laboratory of the Veterinary Faculty of Cáceres. This journey, which took $12 \mathrm{~h}$, occurred at night. The samples were carried in isothermal boxes by a courier with no special precautions. On arrival at the laboratory, the semen doses were stored in a refrigerated incubator (FOC $225 \mathrm{I}$, VELP Scientifica, Usmate, Italy) at $16-17^{\circ} \mathrm{C}$ for 7 days (collection day $=$ day 0 ). On days 1, 4 and 7, two aliquots were extracted from one bottle of each extender. A total of 192 semen samples were analyzed. The following sperm quality parameters were measured in each of the aliquots: motility, viability, acrosome status, plasma membrane fluidity, phosphatidylserine externalization at the plasma membrane of spermatozoa and mitochondrial membrane potential. The motility analysis was carried out by a CASA (Computer Assisted Sperm Analysis) system and the other parameters were measured by flow cytometry.

\subsubsection{Assessment of Sperm Motility}

Immediately after gentle mixing, $1 \mathrm{~mL}$ of semen was taken from each bottle and examined for motility pattern using the CASA system (ISAS ${ }^{\circledR}$ program, Proiser R+D, Paterna, Valencia, Spain). Before the motility analysis, the seminal samples were incubated at $38^{\circ} \mathrm{C}$ for $1 \mathrm{~h}$ (Mini Galaxy A, RS Biotech, United Kingdom). A total of $2 \mu \mathrm{l}$ of sample was placed in a pre-warmed counting chamber (Leja ${ }^{\circledR}$, Luzernestraat, The Netherlands). Sperm motility analysis was based on the examination of 25 consecutive digitalized images obtained from several fields using a 10X negative-phase contrast objective and a heated stage at $38^{\circ} \mathrm{C}$. At least 300 spermatozoa per sample were analyzed. Images were taken with a time lapse of $1 \mathrm{~s}$. The following sperm motility parameters were recorded: total motile spermatozoa (\% TMS, spermatozoa with an average path velocity, VAP $>10 \mu \mathrm{m} / \mathrm{s}$ ), progressively motile spermatozoa (\% PMS, spermatozoa with a straightness coefficient $>0.8,80 \%$ ), VCL (curvilinear velocity in $\mu \mathrm{m} / \mathrm{s}$ ), VSL (straight-line velocity in $\mu \mathrm{m} / \mathrm{s}$ ), VAP (average path velocity in $\mu \mathrm{m} / \mathrm{s}$ ), STR (straightness coefficient in $\%$ ), WOB (wobble coefficient in \%) and ALH (amplitude of lateral head displacement in $\mu \mathrm{m}$ ). Spermatozoa with an average path velocity (VAP) $<10 \mu \mathrm{m} / \mathrm{s}$ were considered immotile. Spermatozoa deviating $<10 \%$ from a straight line were designated as linearly motile and spermatozoa with a radius $<25 \mu \mathrm{m}$ were classified as circularly motile (Saravia et al., 2005).

\subsubsection{Flow Cytometry Analyses}

Flow cytometry analyses were performed using a Coulter EPICS XL-MCL flow cytometer (Beckman Coulter Ltd.) The fluorophores were excited by a $200 \mathrm{mV}$ argon ion laser operating at $488 \mathrm{~nm}$. A total of 10,000 gated events based on the forward scatter and side scatter of the sperm population recorded in the linear mode were collected per sample with a running rate of approximately 500 events/s. The fluorescence data were collected in the logarithmic mode and analyzed using a FACStationTM and EXPOTM 32 ADC software (Beckman Coulter, Inc.).

\subsubsection{Assessment of Sperm Viability}

Fluorescent staining using the LIVE/DEAD Sperm Viability Kit was performed to assess porcine spermatozoa viability (Aparicio et al., 2007). Briefly, $5 \mu \mathrm{l}$ of SYBR-14 $(2 \mu \mathrm{M})$ and $10 \mu \mathrm{l}$ of propidium iodide (PI $5 \mu \mathrm{M})$ were added to $500 \mu \mathrm{L}$ of diluted semen sample $\left(33 \times 10^{6}\right.$ cells $\left./ \mathrm{mL}\right)$ in isotonic buffered diluent Coulter Isoton II and incubated for $20 \mathrm{~min}$ at room temperature in the dark. After incubation, the cells were analyzed and the percentage of viable spermatozoa was expressed as the percentage of SYBR 14 - positive and propidium iodide - negative spermatozoa.

\subsubsection{Assessment of Acrosome Status of Spermatozoa}

The acrosome integrity of the spermatozoa was assessed after staining the spermatozoa with fluorescein isothiocyanate - peanut agglutinin (FITC-PNA), as a marker for acrosomal status, and PI (Waterhouse et al., 2004). Aliquots of $100 \mu \mathrm{L}$ of each semen sample $\left(33 \times 10^{6}\right.$ cells $\left./ \mathrm{mL}\right)$ were incubated at room temperature in the dark for 5 min with $5 \mu \mathrm{L}(1 \mu \mathrm{g} / \mathrm{mL})$ PNA-FITC and $5 \mu \mathrm{L}(6 \mu \mathrm{mol} / \mathrm{L})$ PI. Just prior to flow cytometry, $400 \mu$ l of isotonic buffered diluents was added to each sample and remixed. The cells were analyzed and the percentage of spermatozoa with acrosomes that were damaged or reacted was expressed as the percentage of PNA - positive and PI - negative spermatozoa.

\subsubsection{Assessment of Plasma Membrane Fluidity}

The plasma membrane fluidity of the spermatozoa was assessed by staining the sperm with merocyanine 540 (M540) and plasma membrane permeability was assessed by staining with YoPro-1 (Harrison, Ashworth, \& Miller, 
1996). Aliquots of $100 \mu \mathrm{l}$ of each semen sample $\left(33 \times 10^{6}\right.$ cells $\left./ \mathrm{mL}\right)$ were diluted in $400 \mu \mathrm{l}$ of isotonic buffered diluent containing $75 \mathrm{nmol} / \mathrm{L}$ YoPro- 1 . The samples were then mixed and incubated at $38^{\circ} \mathrm{C}$ for $15 \mathrm{~min}$. Just before flow cytometry, M540 was added to each sample to a final concentration of $2 \mu \mathrm{mol} / \mathrm{L}$, incubated for $2 \mathrm{~min}$ and remixed. After incubation, the cells were analyzed and the results were expressed as the percentage of viable sperm with an unstable plasma membrane (YoPro-1-negative/M-540 - positive).

\subsubsection{Evaluation of the Phosphatidylserine Externalization at the Plasma Membrane of Spermatozoa}

The study of phosphatidylserine (PS) externalization in plasma membrane spermatozoa was performed using Annexin-V-FITC to specifically detect PS translocation from the inner to the outer leaflet of the sperm plasma membrane.

Aliquots of $300 \mu \mathrm{l}$ of each semen sample $\left(33 \times 10^{6}\right.$ cells $\left./ \mathrm{mL}\right)$ were diluted in $200 \mu$ of the following buffer: 96 $\mathrm{mmol} / 1 \mathrm{NaCl}, 4.7 \mathrm{mmol} / 1 \mathrm{KCl}, 0.4 \mathrm{mmol} / 1 \mathrm{MgSO}_{4}, 0.3 \mathrm{mmol} / 1 \mathrm{NaH}_{2} \mathrm{PO}_{4}, 5.5 \mathrm{mmol} / \mathrm{l}$ glucose, $1 \mathrm{mmol} / 1$ sodium pyruvate, $21.6 \mathrm{mmol} / 1$ sodium lactate, $20 \mathrm{mmol} / 1 \mathrm{HEPES}\left(\mathrm{pH} 7.45\right.$ ), and $2.5 \mathrm{mmol} / 1 \mathrm{CaCl}_{2}$. Then, a $100 \mu \mathrm{l}$ aliquot was transferred to a $5 \mathrm{ml}$ tube and stained with $5 \mu \mathrm{l}$ AnnexinV-FITC and $4 \mu \mathrm{l}$ propidium iodide (PI) by incubation for $15 \mathrm{~min}$ in the dark at room temperature. Finally, $400 \mu \mathrm{l}$ of isotonic buffered diluents was added to each sample and mixed before flow cytometry analysis. For statistical analysis, the results were expressed as the percentage of viable sperm with PS externalization (AnnexinV-FITC - positive/PI - negative).

\subsubsection{Assessment of Mitochondrial Membrane Potential Status}

Mitochondrial membrane potential was evaluated using the specific probe JC-1. JC-1 reversibly changes its fluorescence from green (monomeric status) to orange (multimeric status, formation of aggregates, $\mathrm{J}_{a g g}$ ) when the mitochondrial membrane potential is high (Amaral \& Ramalho-Santos, 2010). Because $\mathrm{J}_{\text {agg }}$ formation depends on the chemical environment (Reers, Smith, \& Chen, 1991), seminal samples $(1.2 \mathrm{~mL})$ were centrifuged at $1500 \mathrm{~g}$ for $1.5 \mathrm{~min}$ and the pellet was resuspended in $0.8 \mathrm{~mL}$ of ND-5 extender. From each sperm sample, $100 \mu \mathrm{L}\left(30 \times 10^{6}\right.$ cells $/ \mathrm{mL}$ ) was diluted in $400 \mu \mathrm{L}$ of isotonic buffered diluent containing $0.15 \mathrm{mmol} / \mathrm{L} \mathrm{JC}-1$ and then mixed and incubated at $38^{\circ} \mathrm{C}$ for $30 \mathrm{~min}$. The samples were remixed before flow cytometry analysis. The percentage of orange stained cells was recorded; these cells were defined as the cells with a high mitochondrial membrane potential (hMMP).

\subsection{Statistical Analysis}

The mean and the standard error of the mean were calculated for descriptive analysis. Q-Q plots were used to check for departures from the normal distribution. The effects of extender (ND-5 and 3D) and storage time (1, 4 and 7 days) on seminal characteristics were assessed using a General Linear Model for Repeated Measures. A mixed-effects model (with boars and ejaculates within boars as random effects and extender and storage time as fixed effects) was applied to the experimental design.

All statistical analyses were performed using the libraries Linear and Nonlinear Mixed Effects Models from the statistical package R 3.0.1 (Pinheiro, Bates, Debroy, Sarker, \& The R Development Core Team, 2013). Statistical significance was defined as $\mathrm{p}<0.05,0.001$.

\section{Results}

Table 1 shows the $\mathrm{pH}$, osmolarity and viscosity characteristics of both extenders.

Table 1. Characteristics of ND-5® and ND-5 3D® extenders

\begin{tabular}{lcccc}
\hline Extender & $\mathrm{pH}$ & Osmolarity $(\mathrm{mOsm} / \mathrm{L})$ & Viscosity at $16^{\circ} \mathrm{C}(\mathrm{cP})$ & Viscosity at $38^{\circ} \mathrm{C}(\mathrm{cP})$ \\
\hline ND-5 & 6.9 & 295 & 10 & 8 \\
ND-5 3D & 6.9 & 295 & 13 & 11 \\
\hline
\end{tabular}

cP: centipoise.

Table 2 shows the results of the motility analysis. The increase in viscosity did not modify the percentage of motile spermatozoa (TMS). For the rest of the parameters, the values were significantly different between the extenders for some or all preservation days. 
Table 2. Effects of extender on motility characteristics on specific days after collection

\begin{tabular}{|c|c|c|c|c|c|c|}
\hline Parameter & Extender & Day 1 & Day 4 & Day 7 & $\begin{array}{l}\mathrm{p} \text { value } \\
\text { (time) }\end{array}$ & $\begin{array}{l}\text { Interaction (extender } \mathrm{x} \\
\text { time) }\end{array}$ \\
\hline \multirow{3}{*}{$\begin{array}{l}\text { VCL } \\
(\mu \mathrm{m} / \mathrm{s})\end{array}$} & ND-5 & $71.19 \pm 1.90$ & $74.05 \pm 1.89$ & $78.88 \pm 1.89$ & \multirow{3}{*}{$<0.001$} & \multirow{3}{*}{ n.s. } \\
\hline & ND-5 3D & $55.60 \pm 1.90$ & $62.11 \pm 1.89$ & $65.13 \pm 1.93$ & & \\
\hline & $\begin{array}{l}\mathrm{p} \text { value } \\
\text { (extender) }\end{array}$ & $<0.001$ & $<0.001$ & $<0.001$ & & \\
\hline \multirow{3}{*}{$\begin{array}{l}\text { VSL } \\
(\mu \mathrm{m} / \mathrm{s})\end{array}$} & ND-5 & $49.94 \pm 2.17$ & $49.27 \pm 2.16$ & $48.07 \pm 2.16$ & n.s. & \multirow{3}{*}{ n.s. } \\
\hline & ND-5 3D & $37.00 \pm 2.17$ & $38.41 \pm 2.16$ & $37.50 \pm 2.18$ & n.s. & \\
\hline & $\begin{array}{l}\mathrm{p} \text { value } \\
\text { (extender) }\end{array}$ & $<0.001$ & $<0.001$ & $<0.001$ & & \\
\hline \multirow{3}{*}{$\begin{array}{l}\text { VAP } \\
(\mu \mathrm{m} / \mathrm{s})\end{array}$} & ND-5 & $61.82 \pm 2.00$ & $63.04 \pm 1.99$ & $65.57 \pm 1.99$ & \multirow{3}{*}{$<0.001$} & \multirow{3}{*}{ n.s. } \\
\hline & ND-5 3D & $45.01 \pm 2.00$ & $48.19 \pm 1.99$ & $48.37 \pm 2.02$ & & \\
\hline & $\begin{array}{l}\mathrm{p} \text { value } \\
\text { (extender) }\end{array}$ & $<0.001$ & $<0.001$ & $<0.001$ & & \\
\hline \multirow{3}{*}{ STR } & ND-5 & $0.79 \pm 0.01$ & $0.77 \pm 0.01$ & $0.72 \pm 0.01$ & $<0.001$ & \multirow{3}{*}{0.052} \\
\hline & ND-5 3D & $0.81 \pm 0.01$ & $0.79 \pm 0.01$ & $0.77 \pm 0.01$ & $<0.001$ & \\
\hline & $\begin{array}{l}\mathrm{p} \text { value } \\
\text { (extender) }\end{array}$ & 0.018 & 0.017 & $<0.001$ & & \\
\hline \multirow{3}{*}{ WOB } & ND-5 & $0.86 \pm 0.01$ & $0.84 \pm 0.01$ & $0.82 \pm 0.01$ & $<0.001$ & \multirow{3}{*}{0.017} \\
\hline & ND-5 3D & $0.82 \pm 0.01$ & $0.78 \pm 0.01$ & $0.75 \pm 0.01$ & $<0.001$ & \\
\hline & $\begin{array}{l}\mathrm{p} \text { value } \\
\text { (extender) }\end{array}$ & $<0.001$ & $<0.001$ & $<0.001$ & & \\
\hline \multirow{3}{*}{$\begin{array}{l}\text { ALH } \\
(\mu \mathrm{m})\end{array}$} & ND-5 & $2.14 \pm 0.04$ & $2.29 \pm 0.04$ & $2.55 \pm 0.04$ & \multirow{3}{*}{$<0.001$} & \multirow{3}{*}{ n.s. } \\
\hline & ND-5 3D & $1.99 \pm 0.04$ & $2.26 \pm 0.04$ & $2.40 \pm 0.04$ & & \\
\hline & $\begin{array}{l}\mathrm{p} \text { value } \\
\text { (extender) }\end{array}$ & 0.005 & n.s. & 0.008 & & \\
\hline \multirow{3}{*}{$\begin{array}{l}\text { BCF } \\
(\mu \mathrm{m})\end{array}$} & ND-5 & $8.09 \pm 0.11$ & $7.86 \pm 0.11$ & $7.76 \pm 0.11$ & 0.019 & \multirow{3}{*}{$<0.001$} \\
\hline & ND-5 3D & $8.21 \pm 0.11$ & $8.92 \pm 0.11$ & $9.33 \pm 0.11$ & $<0.001$ & \\
\hline & $\begin{array}{l}\mathrm{p} \text { value } \\
\text { (extender) }\end{array}$ & n.s. & $<0.001$ & $<0.001$ & & \\
\hline \multirow{3}{*}{$\begin{array}{l}\text { TMS } \\
(\%)\end{array}$} & ND-5 & $87.3 \pm 0.02$ & $85.8 \pm 0.02$ & $82.0 \pm 0.02$ & \multirow{3}{*}{$<0.001$} & \multirow{3}{*}{ n.s. } \\
\hline & ND-5 3D & $87.8 \pm 0.02$ & $86.7 \pm 0.02$ & $82.5 \pm 0.02$ & & \\
\hline & $\begin{array}{l}\mathrm{p} \text { value } \\
\text { (extender) }\end{array}$ & n.s. & n.s. & n.s. & & \\
\hline \multirow{3}{*}{$\begin{array}{l}\text { PMS } \\
(\%)\end{array}$} & ND-5 & $56.1 \pm 0.03$ & $48.7 \pm 0.03$ & $40.3 \pm 0.03$ & \multirow{3}{*}{$<0.001$} & \multirow{3}{*}{ n.s. } \\
\hline & ND-5 3D & $59.1 \pm 0.03$ & $53.1 \pm 0.03$ & $47.8 \pm 0.03$ & & \\
\hline & $\begin{array}{l}\mathrm{p} \text { value } \\
\text { (extender) }\end{array}$ & n.s. & 0.012 & 0.001 & & \\
\hline
\end{tabular}

TMS indicates percentage of total motile sperm; PMS, percentage of progressively motile sperm. Values are means \pm standard error of the mean (SEM).

n. s.: not significant $(\mathrm{p}>0.05)$.

It is worth noting that both the STR, which indicates the straightness of the sperm trajectory, and the percentage of spermatozoa with progressive motility were higher in $3 \mathrm{D}$. The differences between extenders were not the same throughout the preservation period; the difference was higher on day 7 in relation to days 1 and 4 . On day 7, STR 
increased $6.9 \%$ on average in 3D in relation to the ND-5 extender, whereas on days 1 and 4 , a $2.5 \%$ and $2.6 \%$ increase was observed, respectively. Regarding the percentage of spermatozoa with progressive motility, a $9 \%$ increase (day 4) and an $18.6 \%$ increase (day 7) was obtained with the 3D extender.

It can also be seen that values for the velocity parameters VCL, VSL and VAP were higher in the ND-5 non-viscous extender; however, for these variables, the behavior of each extender through the storage period was no different, with no effect of storage time in the case of VSL.

The amplitude of lateral head displacement (ALH) was lower in the 3D extender, whereas flagellar beat cross frequency (BCF) was higher, given the higher viscosity of the medium. In addition, for BCF, the behavior throughout the storage time was different for each extender: there was a decrease over time in the ND-5 extender and an increase in the 3D extender.

Table 3 shows the results for the sperm quality variables in both extenders as measured by flow cytometry.

Table 3. Effects of extender on flow cytometry characteristics on specific days after collection

\begin{tabular}{|c|c|c|c|c|c|c|}
\hline Parameter & Extender & Day 1 & Day 4 & Day 7 & $\begin{array}{l}\mathrm{p} \text { value } \\
\text { (time) }\end{array}$ & $\begin{array}{l}\text { Interaction } \\
\text { (extender } \mathrm{x} \text { time) }\end{array}$ \\
\hline \multirow{3}{*}{ VS } & ND-5 & $92.59 \pm 0.46$ & $93.32 \pm 0.45$ & $93.34 \pm 0.45$ & \multirow{2}{*}{ n.s. } & \multirow{2}{*}{ n.s. } \\
\hline & ND-5 3D & $93.75 \pm 0.46$ & $93.27 \pm 0.45$ & $93.79 \pm 0.45$ & & \\
\hline & $\begin{array}{l}\mathrm{p} \text { value } \\
\text { (extender) }\end{array}$ & n.s. & n.s. & n.s. & \multirow{4}{*}{ n.s. } & \multirow{4}{*}{ n.s. } \\
\hline \multirow{3}{*}{ DAS } & ND-5 & $6.93 \pm 0.96$ & $7.60 \pm 0.95$ & $7.73 \pm 0.95$ & & \\
\hline & ND-5 3D & $3.24 \pm 0.96$ & $3.40 \pm 0.95$ & $3.47 \pm 0.95$ & & \\
\hline & $\begin{array}{l}\mathrm{p} \text { value } \\
\text { (extender) }\end{array}$ & $<0.001$ & $<0.001$ & $<0.001$ & & \\
\hline \multirow{3}{*}{ VUM } & ND-5 & $6.80 \pm 0.43$ & $9.11 \pm 0.42$ & $8.67 \pm 0.42$ & 0.001 & \multirow{3}{*}{0.028} \\
\hline & ND-5 3D & $5.86 \pm 0.43$ & $6.24 \pm 0.42$ & $6.74 \pm 0.44$ & n.s. & \\
\hline & $\begin{array}{l}\mathrm{p} \text { value } \\
\text { (extender) }\end{array}$ & n.s. & $<0.001$ & $<0.001$ & & \\
\hline \multirow{3}{*}{ EPS } & ND-5 & $8.93 \pm 0.64$ & $10.45 \pm 0.78$ & $11.27 \pm 0.87$ & \multirow{3}{*}{ n.s. } & \multirow{3}{*}{ n.s. } \\
\hline & ND-5 3D & $5.77 \pm 0.62$ & $6.04 \pm 0.78$ & $7,74 \pm 1.00$ & & \\
\hline & $\begin{array}{l}\mathrm{p} \text { value } \\
\text { (extender) }\end{array}$ & $<0.001$ & $<0.001$ & $<0.001$ & & \\
\hline \multirow{3}{*}{ hMMP } & ND-5 & $76.95 \pm 3,94$ & $73.36 \pm 5,52$ & $79.93 \pm 3,39$ & \multirow{3}{*}{ n.s. } & \multirow{3}{*}{ n.s. } \\
\hline & ND-5 3D & $81.87 \pm 3,67$ & $79.77 \pm 3,21$ & $80.54 \pm 2,61$ & & \\
\hline & $\begin{array}{l}\mathrm{p} \text { value } \\
\text { (extender) }\end{array}$ & $<0.001$ & n.s. & n.s. & & \\
\hline
\end{tabular}

VS indicates viable spermatozoa with an intact plasma membrane (SYBR-14+/PI -); DAS, viable spermatozoa with a damaged acrosome (PNA+/PI-); VUM, viable spermatozoa with an unstable plasma membrane; EPS, viable spermatozoa with phosphatidylserine externalization in plasma membrane; hMMP, spermatozoa with high mitochondrial membrane potential; MF, mean fluorescence intensity (JC-1).

Values are means \pm standard error of the mean (SEM).

n. s.: not significant $(\mathrm{p}>0.05)$.

There were no differences between the extenders in the percentage of viable spermatozoa with an intact plasma membrane (VS). The percentage of spermatozoa with a high mitochondrial membrane potential (hMMP) was only different on day $1(\mathrm{p}<0.001)$, with higher values for the 3D extender. Indeed, for the live spermatozoa population, a 4 point average reduction in the percentage of spermatozoa with damaged acrosomes (DAS) (reduction of 54.5\%) $(\mathrm{p}<0.001)$ and in the percentage of spermatozoa with PS externalization at the plasma membrane (EPS) 
(reduction of $36.2 \%$ ) was obtained with the 3D extender, a decrease that remained constant throughout the 7 preservation days. The use of this extender also resulted in a significant decrease $(p<0.001)$ in the percentage of spermatozoa with an unstable plasma membrane (VUM) on days 4 and 7 (M540 - negative/YoPro-1- negative spermatozoa).

\section{Discussion}

The sperm velocity parameters were different for the two extenders. The most likely reason for this is their different densities. It has been shown that the viscosity of the medium surrounding the spermatozoon influences its movement (Hirai et al., 1997; Hunter, Coy, Gadea, \& Rath, 2011; Kirkman-Brown \& Smith 2011; Smith, Gaffney, Gadelha, Kapur, \& Kirkman-Brown, 2009). Thus, in the case of a bull spermatozoon, the flagellar beat frequency decreases almost exactly with the square root of the viscosity (Rikmenspoel, 1984). While the hyperactive movement of a mouse spermatozoon is not linear in a low viscosity medium, it becomes more linear in a highly viscous or viscoelastic solution (Suárez \& Dai, 1992). Our results are a further contribution to the study of the significant differences in the motility of spermatozoa in media of differing viscosity, and the greater consideration that this fact is being given in the measurement of in vitro motility, with a view to their subsequently being correlated to in vivo motility. Our study shows that an increase in the viscosity of the extender produced a reduction in the VCL, VSL and VAP velocity parameters. These results are similar to those reported by Suárez and Dai (1992) for mouse spermatozoa.

The number of motile spermatozoa, in particular those with progressive motility, is one of the most frequent measures used to estimate the quality of an ejaculate, given its importance for sperm migration through the female genital tract and penetration of the oocyte membrane. Thus, it is considered to be one of the factors determining in vitro fertilization rates (Simon \& Lewis, 2011; Turner, 2006). In this study, the 3D viscous extender produced an increase both in the straightness of the trajectory of the spermatozoa and in the percentage with progressive motility. In addition, the difference between the extenders was greater at the end of the preservation period. Coy et al. (2009) used a plant extract to increase the viscosity of a medium for swine spermatozoa and observed an increase in the STR index and the percentage of progressively motile spermatozoa, although they also reported lower VCL, VSL and VAP values in comparison to the control medium. Corcini et al. (2011) found an increase in the percentage of motile spermatozoa after adding gelatin to the BTS extender for short term (three days) preserved swine semen. In our study, this parameter was not different between the extenders. The literature suggests that changes to motility parameters are dependent on the agent used to increase the viscosity (because it determines whether liquefaction will occur at the temperature at which motility is measured), as well as the degree of viscosity (Corcini et al., 2011; Coy et al., 2009; Salvador et al., 2006; Yániz et al., 2005). Different viscous media, therefore, influence the motility characteristics of the spermatozoa.

Various authors have indicated the importance of in vitro evaluation of sperm motility in viscous media. During transit through the sow's genital tract, the spermatozoon is surrounded by fluids that are not only of different chemical composition but also of different viscosity. The oviduct secretes a viscous glycoprotein (Hunter, 2002; Hunter, 2005; Jansen, 1978; Jansen, 1980). In experimental in vitro conditions, however, the level of viscosity is very low, close to that of water, which is very much lower than that of the oviduct. According to Coy et al. (2009), a certain degree of viscosity is desirable in order for the spermatozoon to interact with the oocyte in vitro (culture medium) or in vivo (oviduct) once it is no longer in contact with seminal plasma components. For this reason, they suggest that the viscosity of the medium is a parameter that must be taken into account when in vitro or in vivo experiments are being designed. Smith et al. (2009) also noted the need to measure sperm motility in media with viscosity similar to that found in uterine physiological conditions. In their study, they note how viscosity significantly affects sperm characteristics, such as planarity, torsion, wave form, trajectory and sperm progression and beat cross frequency, modifications that were observed in our study (BCF, ALH and WOB parameters). Those authors conclude that observations carried out in low viscosity liquids, which is the case in the majority of in vitro experiments, can provide little information with regard to motility in vivo. Furthermore, the fact that a viscous medium reduces the rolling rate allows the full waveform to be captured in a precise way for a period of one or more beats, which is convenient for bi-dimensional techniques for measuring flagellar movement. In the view of these researchers, given the important advances which are being made in the digital capture and processing of high-speed images, the use of a viscous medium has the advantage of allowing a more detailed analysis of the development and propagation of the flagellar wave and so establishes a better correlation between cellular progression in liquids with viscosities similar to physiological ones. These are matters that will surely be taken into consideration in the development of the new generation of CASA systems.

Various studies have attempted to relate the CASA parameters with in vivo fertility results. The results are contradictory (Broekhuijse, Sostaric, Feitsma, \& Gadella, 2012; Budworth, Amann, \& Chapman, 1988; Didion, 
2008; Liu, Clake, \& Baker, 1991). Because spermatozoa exposed to a viscous medium have a greater capacity to move, unite with and penetrate the oocyte under in vitro conditions (Coy et al., 2009), and their movements are more similar to those that occur in the oviduct, it would be interesting if future studies were to correlate the motility in viscous solutions with fertility results.

The 3D viscous extender produced a reduction in the number of spermatozoa with damaged acrosomes and an unstable plasma membrane. These are standard parameters for measuring semen quality. This favorable effect on semen quality was observed by Nagy et al. (2002) in rabbit spermatozoa suspended in an extender with gelatin. Coy et al. (2009) also found greater viability and less generation of reactive oxygen species in swine spermatozoa extended in Androhep ${ }^{\circledR}$ (Minitube, Germany) to which a powdered plant extract was added to increase its viscosity, compared with the viscosity achieved using Androhep ${ }^{\circledR}$ on its own. Unlike other studies (Coy et al., 2009; Nagy et al., 2002; Yániz et al., 2005), we did not find an increase in sperm viability with the viscous extender.

The liquid preservation of boar semen is associated with apoptotic-like changes in the sperm, such as a decrease in the mitochondrial membrane potential and externalization of phosphatidylserine from the inner to the outer leaflet of the sperm membrane (Trzcinska, Bryla, \& Smorag, 2011). A decrease in the mitochondrial membrane potential of spermatozoa has frequently been associated with an increase in the number of abnormalities in the semen (Espinoza, Schulz, Sánchez, \& Villegas, 2009) and a reduction in fertility (Gallon, C. Marchetti, Jouy, \&P. Marchetti, 2006; Grunewald, Said, Paasch, Glander, \& Agarwal, 2008). The percentage of spermatozoa with high mitochondrial potential did not differ significantly between extenders except on day 1 , when the value for the viscous extender was higher, although there was a tendency towards greater values in the samples diluted in the viscous extender through the storage period.

The assessment of PS externalization is included in the evaluation of cooling - induced damage to spermatozoa. The number of spermatozoa with these early apoptotic changes has been correlated with poor fertility in breeding bulls (Anzar, He, Buhr, Kroestsch, \& Pauls, 2002) and with male infertility in humans (P. Marchetti \& C. Marchetti, 2007). In this study, the 3D viscous extender was associated with a reduction in the number of spermatozoa with PS externalization at the plasma membrane of spermatozoa. We cannot compare our results with other authors because this parameter is not reported in other studies.

The mechanism by which the 3D extender improves sperm quality remains unclear. López-Gatius et al. (2005) suggest that a viscous medium, because it limits the movement of the spermatozoa during storage, also probably causes a reduction in the metabolic demands made on them. According to Nagy et al. (2002), even when buffers are added to the extenders to minimize $\mathrm{pH}$ fluctuations, the sedimentation which inevitably occurs during the preservation probably leads to a lowering of the $\mathrm{pH}$ in the region of the sedimented cells as a result of the accumulation of toxic metabolites. Because the gelling extender (solid storage) avoids sedimentation, there is a more homogenous distribution of the spermatozoa, which in turn allows the buffer to act more efficiently. The spermatozoa also benefit from a more homogenous distribution of the various components of the suspension. However, in this study, the slight increase in 3D extender viscosity was not enough to maintain the spermatozoa in suspension through the storage period, and sedimentation was inevitable. The proposed justification is, in this case, not applicable. On the other hand, sperm microencapsulation in barium alginate membranes protects sperm cells during storage. This procedure has been shown to preserve morpho-functional characteristics such as motility, in situ enzymatic activity and acrosome integrity (Spinaci et al., 2013; Torre et al., 2000; Vigo et al., 2002). An explanation is that the "dilution shock" (Watson, 1995), with its damaging effects, that spermatozoa suffer when they are stored under refrigeration in extender is avoided. In our study, the fact that sedimentation and dilution were not avoided during storage suggests that some protective effect of the viscous medium is present. More research needs to be done to confirm this statement, including field fertility trials.

\section{Conclusion}

The use of the Zoosperm ND-5 3D® viscous extender for the long-term storage of swine semen improves sperm quality in terms of a lower percentage of spermatozoa with unstable plasma membranes, externalization of PS and damaged acrosomes. These results introduce a new possibility in the design of new boar extenders for different storage conditions.

\section{Acknowledgments}

This work has been granted by a collaboration agreement between Extremadura University and Import-Vet, S. A. We also thank the company Proporseg, Segovia, Spain, for the use of their facilities and animals, and also thank the veterinarians of the company, Alfonso Ageda and César del Prisco, for their invaluable collaboration. 


\section{References}

Amaral, A., \& Ramalho-Santos, J. (2010). Assessment of mitochondrial potential: implications for the correct monitoring of human sperm function. International Journal of Andrology, 33(1), e180-e186. http://dx.doi.org/10.1111/j.1365-2605.2009.00987.x

Anzar, M., He, L., Buhr, M. M., Kroetsch, T. G., \& Pauls, K. P. (2002). Sperm apoptosis in fresh and cryopreserved bull semen detected by flow cytometry and its relationship with fertility. Biology of Reproduction, 66(2), 354-360. http://dx.doi.org/10.1095/biolreprod66.2.354

Aparicio, I. M., Bragado, M. J., Gil, M. C., García-Herreros, M., González-Fernández, L., Tapia, J. A., \& García-Marín, L. J. (2007). Phosphatidylinositol 3-kinase pathway regulates sperm viability but not capacitation on boar spermatozoa. Molecular Reproduction and Development, 74(8), 1035-1042. http://dx.doi.org/10.1002/mrd.20663

Boe-Hansen, G. B., Ersboll, A. K., Greve, T., \& Christensen, P. (2005). Increasing storage time of extended boar semen reduces sperm DNA integrity. Theriogenology, 63(7), 2006-2019. http://dx.doi.org/10.1016/j.theriogenology.2004.09.006

Broekhuijse, M. L., Sostaric, E., Feitsma, H., \& Gadella, B. M. (2012). Application of computer-assisted semen analysis to explain variations in pig fertility. Journal of Animal Science, 90(3), 779-789. http://dx.doi.org/10.2527/jas.2011-4311

Budworth, P. R., Amann, R. P., \& Chapman, P. L. (1988). Relationships between computerized measurements of motion of frozen-thawed bull spermatozoa and fertility. Journal of Andrology, 9(1), 41-54.

Conejo-Nava, J., Fierro, R., Gutiérrez, C. G., \& Betancourt, M. (2003). Membrane status and in vitro capacitation of porcine sperm preserved in long-term extender at 16 degrees C. Archives of Andrology, 49(4), 287-295. http://dx.doi.org/10.1080/01485010390204931

Corcini, C. D., Moreira, F., Pigozzo, R., Varela, A. S., Torres, N. U., \& Lucia, T. (2011). Semen quality and reproductive performance after artificial insemination with boar sperm stored in a gelatin-suplemented extender. Livestock Sciences, 138(1), 289-292. http://dx.doi.org/10.1016/j.livsci.2010.11.019

Coy, P., Gadea, J., Rath, D., \& Hunter, R. H. (2009). Differing sperm ability to penetrate the oocyte in vivo and in vitro as revealed using colloidal preparations. Theriogenology, 72(9), 1171-1179. http://dx.doi.org/10.1016/j.theriogenology.2009.07.011

De Ambrogi. M., Ballester, J., Saravia, F., Caballero, I., Johannisson, A., Wallgren, M., Andersson, M., \& Rodríguez-Martínez, H. (2006). Effect of storage in short-and long-term commercial semen extenders on the motility, plasma membrane and chromatin integrity of boar spermatozoa. International Journal of Andrology, 29(5), 543-552. http://dx.doi.org/10.1111/j.1365-2605.2006.00694.x

Didion, B. A. (2008). Computer-assisted semen analysis and its utility for profiling boar semen samples. Theriogenology, 70(8), 1374-1376. http://dx.doi.org/10.1016/j.theriogenology.2008.07.014

Dubé, C., Beaulieu, M., Reyes-Moreno, C., Guillemette, C., \& Bailey, J. L. (2004). Boar sperm storage capacity of BTS and Androhep Plus: viability, motility, capacitation, and tyrosine phosphorylation. Theriogenology, 62(5), 874-886. http://dx.doi.org/10.1016/j.theriogenology.2003.12.006

Espinoza, J. A., Schulz, M. A., Sánchez, R., \& Villegas, J. V. (2009). Integrity of mitochondrial membrane potential reflects human sperm quality. Andrologia, 41(1), 51-54. http://dx.doi.org/10.1111/j.1439-0272.2008.00878.x

Gadea, J. (2003). Review: semen extenders used in the artificial insemination of swine. Journal of Agricultural Research, 1, 17-27. http://dx.doi.org/10.1016/j.fertnstert.2006.03.055

Gallon, F., Marchetti, C., Jouy, N., \& Marchetti, P. (2006). The functionality of mitochondria differentiates human spermatozoa with high and low fertilizing capability. Fertility and Sterility, 86(5), 1526-1530.

Grunewald, S., Said, T. M., Paasch, U., Glander, H. J., \& Agarwal, A. (2008). Relationship between sperm apoptosis signalling and oocyte penetration capacity. International Journal of Andrology, 31(3), 325-330. http://dx.doi.org/10.1111/j.1365-2605.2007.00768.x

Harrison, R. A., Ashworth, P. J., \& Miller, N. G. (1996). Bicarbonate/ $\mathrm{CO}_{2}$, an effector of capacitation, induces a rapid and reversible change in the lipid architecture of boar sperm plasma membranes. Molecular Reproduction and Development, 378-391. http://dx.doi.org/10.1002/(SICI)1098-2795(199611)45:3<378::AID-MRD16>3.0.CO;2-V 
Hirai, M., Cerbito, W. A., Wijayagunawardane, M. P., Braun, J., Leidl, W., Ohosaki, K., Matsuzawa, T., Miyazawa, K., \& Sato, K. (1997). The effect of viscosity of semen diluents on motility of bull spermatozoa. Theriogenology, 47(7), 1463-1478.http://dx.doi.org/10.1016/S0093-691X(97)00136-2

Hunter, R. H. (2002). Vital aspects of Fallopian tube physiology in pigs. Reproduction in Domestic Animals, 37(4), 186-190. http://dx.doi.org/10.1046/j.1439-0531.2002.00376.x

Hunter, R. H. (2005). The Fallopian tubes in domestic mammals: how vital is their physiological activity? Reproduction, Nutrition, Development, 45(3), 281-290. http://dx.doi.org/10.1007/s10815-010-9531-3

Hunter, R. H., Coy, P., Gadea, J., \& Rath, D. (2011). Considerations of viscosity in the preliminaries to mammalian fertilisation. Journal of Assisted Reproduction and Genetic, 28(3), 191-197.

Huo, L. J., Ma, X. H., \&Yang, Z. M. (2002). Assessment of sperm viability, mitochondrial activity, capacitation and acrosome intactness in extended boar semen during long-term storage. Theriogenology, 58(7), 1349-1360. http://dx.doi.org/10.1016/S0093-691X(02)00953-6

Jansen, R. P. (1978). Fallopian tube isthmic mucus and ovum transport. Science, 201(4353), 349-351.

Jansen, R. P. (1980). Cyclic changes in the human fallopian tube isthmus and their functional importance. American Journal of Obstetric and Gynecology, 136(3), 292-308.

Johnson, L. A., Weitze, K. F., Fiser, P., \& Maxwell, W. M. (2000). Storage of boar semen. Animal Reproduction Science, 62(1-3), 143-172. http://dx.doi.org/10.1016/S0378-4320(00)00157-3

Kirkman-Brown, J. C., \& Smith, D. J. (2011). Sperm motility: is viscosity fundamental to progress? Molecular Human Reproduction, 17(8), 539-544. http://dx.doi.org/10.1093/molehr/gar043

Kuster, C. E., \& Althouse, G. C. (1999). The fecundity of porcine semen stored for 2 to 6 days in Androhep and X-CELL extenders. Theriogenology, 52(3), 365-376. http://dx.doi.org/10.1016/S0093-691X(99)00135-1

Liu, D. Y., Clarke, G. N., \& Baker, H. W. (1991). Relationship between sperm motility assessed with the Hamilton-Thorn motility analyzer and fertilization rates in vitro. J Androl, 12(4), 231-239.

López-Gatius, F., Sances, G., Sancho, M., Yániz, J., Santolaria, P., Gutiérrez, R., ... Soler, C. (2005). Effect of solid storage at 15 degrees $\mathrm{C}$ on the subsequent motility and fertility of rabbit semen. Theriogenology, 64(2), 252-260. http://dx.doi.org/10.1016/j.theriogenology.2004.11.015

Marchetti, P., \& Marchetti, C. (2007). Impact and significance of apotosis in human ejaculated spermatozoa. C.R. Kettleworth: Nova Publishers.

Martín-Hidalgo, D., Barón, F. J., Robina, A., Bragado, M. J., Llera, A. H., García-Marín, L. J., \& Gil, M. C. (2013). Inter- and intra-breed comparative study of sperm motility and viability in Iberian and Duroc boar semen during long-term storage in MR-A and XCell extenders. Animal Reproduction Science, 139(1-4), 109-114. http://dx.doi.org/10.1016/j.anireprosci.2013.04.001

Nagy, S., Sinkovics, G., \& Kovacs, A. (2002). Viability and acrosome integrity of rabbit spermatozoa processed in a gelatin-supplemented extender. Animal Reproduction Science, 70(3-4), $283-286$. http://dx.doi.org/10.1016/S0378-4320(01)00189-0

Pinheiro, J., Bates, D., Debroy, S., Sarker, D., \& The R Development Core Team (2013). nlme: Linear and Nonlinear Mixed Effects Model. R package version, 3.1-111.

Reers, M., Smith, T. W., \& Chen, L. B. (1991). J-aggregate formation of a carbocyanine as a quantitative fluorescent indicator of membrane potential. Biochemistry, 30(18), 4480-4486. http://dx.doi.org/10.1021/bi00232a015

Riesenbeck, A. (2011). Review on international trade with boar semen. Reproduction in Domestic Animals, 46(Suppl 2), 1-3. http://dx.doi.org/10.1111/j.1439-0531.2011.01869.x

Rikmenspoel, R. (1984). Movements and active moments of bull sperm flagella as a function of temperature and viscosity. The Journal of Experimental Biology, 108, 205-230.

Roca, J., Vázquez, J. M., Gil, M. A., Cuello, C., Parrilla, I., \& Martínez, E. A. (2006). Challenges in pig artificial insemination. Reproduction in Domestic Animals, 41(Suppl 2), 43-53. http://dx.doi.org/10.1111/j.1439-0531.2006.00768.x

Rosato, M., \& Iaffaldano, N. (2011). Effect of chilling temperature on the long-term survival of rabbit spermatozoa held either in a tris-based or a jellified extender. Reproduction in Domestic Animals, 46(2), 301-308. http://dx.doi.org/10.1111/j.1439-0531.2010.01667.x 
Salvador, I., Yániz, J., Viudes-de-Castro, M. P., Gómez, E. A., \& Silvestre, M. A. (2006). Effect of solid storage on caprine semen conservation at 5 degrees C. Theriogenology, 66(4), 974-981. http://dx.doi.org/10.1016/j.theriogenology.2006.02.042

Saravia, F., Wallgren, M., Nagy, S., Johannisson, A., \& Rodríguez-Martínez, H. (2005). Deep freezing of concentrated boar semen for intra-uterine insemination: effects on sperm viability. Theriogenology, 63(5), 1320-1333. http://dx.doi.org/10.1016/j.theriogenology.2004.06.012

Simon, L., \& Lewis, S. E. (2011). Sperm DNA damage or progressive motility: which one is the better predictor of fertilization in vitro? Systems Biology in Reproductive Medicine, 57(3), 133-138.

Smith, D. J., Gaffney, E. A., Gadelha, H., Kapur, N., \& Kirkman-Brown, J. C. (2009). Bend propagation in the flagella of migrating human sperm, and its modulation by viscosity. Cell Motility and the Cytoskeleton, 66(4), 220-236. http://dx.doi.org/10.1002/cm.20345

Spinaci, M., Chlapanidas, T., Bucci, D., Vallorani, C., Perteghella, S., Lucconi, G., ... Torre, M. L. (2013). Encapsulation of sex sorted boar semen: sperm membrane status and oocyte penetration parameters. Theriogenology, 79(4), 575-581. http://dx.doi.org/10.1016/j.theriogenology.2012.10.021

Suárez, S. S., \& Dai, X. (1992). Hyperactivation enhances mouse sperm capacity for penetrating viscoelastic media. Biology of Reproduction, 46(4), 686-691. http://dx.doi.org/10.1095/biolreprod46.4.686

Torre, M. L., Maggi, L., Vigo, D., Galli, A., Bornaghi, V., Maffeo, G., \& Conte, U. (2000). Controlled release of swine semen encapsulated in calcium alginate beads. Biomaterials, 21(14), 1493-1498. http://dx.doi.org/10.1016/S0142-9612(00)00035-1

Trzcinska, M., Bryla, M., \& Smorag, Z. (2011). Apoptotic-like changes in the spermatozoa of fresh and stored boar semen and the quality of embryos produced in vivo. Animal Reproduction Science, 124(1-2), 90-97. http://dx.doi.org/10.1016/j.anireprosci.2011.02.016

Turner, R. M. (2006). Moving to the beat: a review of mammalian sperm motility regulation. Reproduction, Fertility and Development, 18(1-2), 25-38. http://dx.doi.org/10.1071/RD05120

Vigo, D., Faustini, M., Torre, M. L., Pecile, A., Villani, S., Asti, A., ... Maffeo, G. (2002). Boar semen controlled-delivery system: morphological investigation and in vitro fertilization test. Reproduction, Fertility and Development, 14(5-6), 307-314. http://dx.doi.org/10.1071/RD02004

Waberski, D., Henning, H., \& Petrunkina, A. M. (2011). Assessment of storage effects in liquid preserved boar semen. Reproduction in Domestic Animals, 46(Suppl 2), 45-48. http://dx.doi.org/10.1111/j.1439-0531.2011.01836.x

Waberski, D., Medings, S., Dirksaen, G., Weitze, K. F., Lewiding, C., \& Hahn, R. (1994). Fertility of long term-stored boar semen: influence of extender (Androhep and Kiev), storage time and plasma droplets in the semen. Animal Reproduction Science, 36, 145-151. http://dx.doi.org/10.1016/0378-4320(94)90061-2

Waterhouse, K. E., De Angelis, P. M., Haugan, T., Paulenz, H., Hofmo, P. O., \& Farstad, W. (2004). Effects of in vitro storage time and semen-extender on membrane quality of boar sperm assessed by flow cytometry. Theriogenology, 62(9), 1638-1651. http://dx.doi.org/10.1016/j.theriogenology.2004.03.001

Watson, P. F. (1995). Recent developments and concepts in the cryopreservation of spermatozoa and the assessment of their post-thawing function. Reproduction, Fertility and Development, 7(4), 871-891. http://dx.doi.org/10.1071/RD9950871

Yániz, J., Marti, J. I., Silvestre, M. A., Folch, J., Santolaria, P., Alabart, J. L., \& López-Gatius, F. (2005). Effects of solid storage of sheep spermatozoa at 15 degrees $\mathrm{C}$ on their survival and penetrating capacity. Theriogenology, 64(8), 1844-1851. http://dx.doi.org/10.1016/j.theriogenology.2005.04.012

\section{Copyrights}

Copyright for this article is retained by the author(s), with first publication rights granted to the journal.

This is an open-access article distributed under the terms and conditions of the Creative Commons Attribution license (http://creativecommons.org/licenses/by/3.0/). 